\title{
Editorial \\ Three years of steady growth for APT - but where next?
}

\author{
Andrew Sims
}

Advances in Psychiatric Treatment has now been in publication for nearly three years. The size of each issue has doubled since the journal was started, and the number of subscriptions has grown, as of 1 March 1997, to 1429 combined with registration for Continuing Professional Development (CPD) and 383 without - a grand total of 1812, deserving of this Overture.

Like any recently mobile and articulate toddler it is still experimenting with what it can do successfully and what results only in intellectual cataplexy. We want to enlist your help in this. Have you enjoyed this issue and found it useful, stimulating, controversial? No? I am sorry, but we will never know unless you write to us. Please correspond. Unless we find ourselves needing legal advice, we will almost certainly publish your letter. The continuing professional development of consultants should not be a didactic, unidimensional exercise of us informing you, but should involve learning together, argument, reformulation and consensus.

I have a problem for which I would like the benefit of your advice. Some British psychiatrists are finding APT quite useful - and some even read it. Some trainees are also getting hold of it, perhaps because they believe their examiners use it as their knowledge base. That is all very agreeable and reassures us, the Editorial Board, that we are doing something useful. There are also a number of overseas psychiatrists, especially those from countries where psychiatry is not yet fully developed, who have seen issues of $A P T$ and would like to have it available locally for themselves and their colleagues, but have neither the means nor the foreign currency to buy it. Now, when we launched the whole CPD enterprise, it was on the understanding that there would be no additional costs to the College. My problem is how to send free copies of every issue to deserving recipients overseas. I would welcome your suggestions. I have had requests from Eastern Europe, several Asian countries, and Africa.

I want to tell you some news that I am very pleased about. Until now I have been both Editor of this journal and Director of CPD in the College. However, from the beginning of April, Professor Gethin Morgan has replaced me as Director of CPD and he is now joining the Editorial Board of this journal. I shall remain Editor and return the compliment by representing $A P T$ on the CPD Committee, which he now chairs. Gethin Morgan is a past Chief Examiner of the College, during which time he was responsible for implementing a number of changes. He has recently retired from the Chair of Mental Health in Bristol. During his many years in the south-west of England he always showed immense and even pastoral concern for consultant psychiatrists spread along more than 200 miles of railway line. Like Molière's gentleman who did not know that he had been speaking prose all the time, Gethin was delivering comprehensive CPD long before the term was invented.

Some of you will have met or corresponded with Louise Whalley, our Editorial Assistant who has contributed so much to the success of APT since the preparation of the first issue. She has recently had six months' sabbatical to paint in India. She has now returned and we are very glad to see her back, and we thank Dominic Bentham who succeeded in being such an excellent locum in her absence.

This issue of $A P T$ continues our policy of a pluralistic approach to psychiatric treatment. Of the psychiatric specialities, we have articles in child and old age psychiatry, in substance misuse, forensic psychiatry and learning disability, and also plenty of relevance for the generalist. We cover both psychological and physical treatments and also a certain amount of management of 
services. Our growing number of overseas subscribers will be interested to see two antipodean contributors in this issue. We have recently devoted most of an issue to pharmacotherapy and are planning a series of articles on cognitive therapy in the future.

We are sometimes asked whether all the articles in APT are commissioned or whether it is possible to submit papers. We are pleased to accept some unsolicited articles, which are subject, like the commissioned articles, to the peer review process.
Obviously, we will not accept articles that we do not consider make a contribution to the continuing professional development of psychiatrists and their management of patients.

So where are we going in the next few years? That will depend considerably on messages that filter through from you, the readership. We show no danger yet of running out of ideas, but are they the topics that you want to read about? The only reason why we have not had an article on Jungian neuroimaging is because you have not asked for it.

\section{Conference notice}

\section{Cycles of Abuse: Approaches to Intervention and Treatment}

A two-day conference aimed at psychiatrists working on the abuse cycle will take place on Friday 6 and Saturday 7 June 1997 at the Swallow Royal Hotel in Bristol. The conference will focus on the treatment of victims (6 June) and perpetrators ( 7 June) of abuse and will involve all sections of the College, including those with a forensic concern with perpetrators, as well as child, adult and geriatric groups concerned with victims in their respective age groups.

Speakers on the first day include Michael Crowe on 'Principles of Treatment - Adult Survivors'; Arnon Bentovim on 'The Child Victim in the Family Context'; Sir Herbert Laming, Chief Inspector, Social Services Inspectorate, giving the social services perspective; and Hereward Harrison, Director of Children's Services for ChildLine, with insights regarding care.

The second day will concentrate on the treatment of perpetrators of abuse. Speakers include Dilys Jones, who will present an overview of the treatment of perpetrators; Richard Beckett and Frances Flaxington on linking cognitive and psychodynamic approaches to treatment; and $\mathrm{Greg}^{\prime} \mathrm{O}^{\prime}$ Brien discussing treatments in those with a learning disability. James MacKeith and Anthony Harbour will talk on confidentiality and the legal issues involved.

There will be a choice of eight workshops on both days, covering a variety of treatment approaches to different client groups.

Further details can be obtained from David Hills, Conference Unit, The Royal College of Psychiatrists (tel. 0171235 2351, extension 108; fax 0171259 6507; e-mail dhills@rcpsych.ac.uk). 